\title{
Diretivas antecipadas de vontade: benefícios, obstáculos e limites
}

Maria Inês Nunes ${ }^{1}$, Márcio Fabri dos Anjos ${ }^{2}$

\section{Resumo}

O conceito de diretivas antecipadas de vontade emergiu em resposta ao avanço tecnológico e ao tratamento médico agressivo empregados em situações ambíguas, como no caso de um prognóstico ruim. 0 cerne do presente documento é o exercício da autonomia do paciente. A Resolução 1.995/12 do Conselho Federal de Medicina estabelece os critérios para que qualquer pessoa - desde que maior de idade e plenamente consciente - possa definir junto ao seu médico quais os limites terapêuticos na fase final de sua vida. O documento é facultativo e poderá ser elaborado em qualquer momento da vida e da mesma maneira modificado ou revogado a qualquer tempo. Este artigo tem por propósito discorrer sobre seus benefícios, obstáculos e limites, considerando o vasto número de pesquisas realizadas sobre o tema e as experiências positivas e negativas de outros países no intuito de contribuir para a discussão de sua efetiva utilização no Brasil.

Palavras-chave: Diretivas antecipadas de vontade. Autonomia pessoal. Bioética.

\section{Resumen}

\section{Directivas anticipadas de voluntad: beneficios, obstáculos y limitaciones}

El concepto de directivas anticipadas de voluntad surgió en respuesta al avance tecnológico y al tratamiento médico agresivo, utilizándoselo en situaciones ambiguas, como ante un pronóstico negativo. El núcleo de este documento consiste en el ejercicio de la autonomía del enfermo. La Resolución 1.995/2012 del Consejo Federal de Medicina establece los criterios para que cualquier persona - mayor de edad y plenamente consciente - pueda definir, junto con su médico, los límites terapéuticos en la fase final de su vida. El documento es opcional y puede llevarse a cabo en cualquier momento de la vida y la misma manera modificada o revocada en cualquier forma y tiempo. El propósito de este artículo es discutir los beneficios, obstáculos y las limitaciones considerando la gran cantidad de investigaciones realizada sobre el tema y las experiencias positivas y negativas de otros países, con el fin de aportar a la discusión sobre su utilización de manera efectiva en Brasil. Palabras-clave: Directivas anticipadas. Autonomía personal. Bioética.

\section{Abstract}

\section{The advance directive: benefits, obstacles and limits}

The concept of advance directives emerged in response to the technological progress and aggressive medical treatment being employed in ambiguous situations, as in the case of a bad prognosis. The core of this document is the exercise of the patients' autonomy. The Federal Council of Medicine's 1.995/2012 Resolution establishes the criteria for anyone - provided that the patient is legally old enough and fully aware - to be able to choose together with his/her doctor the therapeutic limits at the end of life. The document is optional and may be completed at any time in life and, in the same way it can be modified or cancelled at any time. The purpose of this article is to consider its benefits, obstacles and limits considering the vast amount of researches carried out on this theme and the positive and negative experiences from other countries in order to contribute to the discussion about its effective use in Brazil.

Key words: Advanced directives. Personal autonomy. Bioethics.

1. Doutora minesnunes18@gmail.com - Universidade de Guarulhos (UnG) e Universidade Santo Amaro (Unisa), São Paulo/SP, Brasil 2. Doutor pesrel@terra.com.br - Centro Universitário São Camilo, São Paulo/SP, Brasil. 
A Resolução 1.995/12 do Conselho Federal de Medicina (CFM) ${ }^{1}$ instigou o interesse da mídia brasileira sobre um tema multifacetado e polêmico: as diretivas antecipadas de vontade (DAV) - também conhecidas como testamento vital ou por seu nome em inglês, living will. No mês seguinte à publicação do documento já repercutiam nos meios de comunicação as opiniões pró e contra de renomados médicos sobre a pertinência da resolução ${ }^{2}$.

Em vigor desde agosto de 2012 a resolução estabelece os critérios para que qualquer pessoa possa definir junto ao seu médico quais os limites terapêuticos na fase terminal - desde que maior de idade e plenamente consciente. A DAV é documento facultativo e poderá ser elaborado, modificado ou revogado em qualquer momento da vida ${ }^{1}$.

O conceito da DAV emergiu em resposta ao avanço tecnológico e ao tratamento médico agressivo empregados em situações ambíguas, como no caso de um prognóstico ruim. As DAV foram designadas para proteger a autonomia do paciente ${ }^{3}$, sob a crença de que este, quando perder sua capacidade de decidir, será por meio desse documento mais respeitado em sua autonomia quanto ao tratamento desejado e/ou quanto ao representante legal que por ele decidirá em tal situação ${ }^{4}$.

Nos últimos 20 anos as diretivas antecipadas foram alvo de muitas publicações, principalmente em relação à falta de conhecimento sobre as mesmas e sua validade legal, que dificulta as relações entre o médico, o paciente e a família ${ }^{5}$. Não obstante os argumentos pró e contra, diversos países têm elaborado instruções apropriadas e legais para sua utilização ${ }^{3}$.

O propósito deste artigo é discorrer sobre os benefícios, obstáculos e limites das DAV na prática clínica, considerando o vasto número de pesquisas realizadas sobre o tema e as experiências positivas e negativas de outros países, no intuito de contribuir para a discussão de sua efetiva utilização no Brasil.

\section{Breve histórico das DAV}

Há pouco mais de quatro décadas o advogado Luis Kutner propôs o testamento vital (living will) como meio de resolução dos conflitos que surgem ao final da vida entre o paciente e o médico em relação às preferências deste por determinados tratamentos ${ }^{6}$.

No Medical Subject Headings (de acordo com o Bioethics thesaurus) 7, "diretivas antecipadas" são definidas como declaração feita com antecedência pelo paciente, na qual está competente para decidir a respeito do seu cuidado, informando sua preferência ou autorizando outra pessoa a decidir por ele. Existem essencialmente dois tipos de diretivas antecipadas: a primeira, na qual o paciente especifica os tratamentos médicos que devem ou não ser fornecidos em certas situações no futuro, também denominadas testamento vital; e a segunda, Durable Power of Attorney (DPA), traduzido como mandato duradouro, que consiste em autorizar outra pessoa (representante legal ou procurador) a decidir em nome do paciente no período em que não este não esteja competente para tal ${ }^{8}$.

As diretivas antecipadas de vontade podem ser divididas em dois subgrupos: 1) afirmação de valor; 2) instrução diretiva. Uma afirmação de valor descreve as preferências gerais e os valores do paciente em relação ao tratamento médico de modo geral, mas não trata de formas específicas de tratamento ou enfermidade. A instrução diretiva expressa a preferência ou recusa por determinado tratamento médico no contexto de determinada doença ${ }^{9}$.

Para promover o uso das DAV nos Estados Unidos da América (EUA) o Congresso aprovou o Patient Self Determination Act (PSDA), vigente a partir de $1^{\circ}$ de dezembro de 1991, enfatizando que todos os hospitais, instituições de longa permanência etc. têm a obrigação legal de desenvolver diretrizes escritas em relação às mesmas e educar os profissionais de saúde sobre a questão, bem como perguntar ao indivíduo que ingressa numa instituição de saúde se já tem uma DAV ou informá-lo de que tem o direito de elaborá-la ${ }^{10}$.

O PSDA foi aprovado em um momento de publicidade de notório caso de obstinação terapêutica, conhecido como o "caso Cruzan" (da jovem estadunidense Nancy Cruzan), e os tribunais forneceram um meio legal para facilitar a tomada de decisão nessas situações. Essa medida foi aprovada quase universalmente pelos bioeticistas, que nela viram um instrumento para proteger a autonomia do paciente. Foi também aceita pelos pacientes, que acreditaram que por meio dela se veriam livres da imposição médica de tratamentos intermináveis e sem sentido; pelos médicos, que confiaram que com essa ferramenta poderiam conhecer os desejos dos pacientes, o que facilitaria a tomada de decisão em situações difíceis, e pelos gestores, que pensaram que tudo isso contribuiria para diminuir os custos da assistência de saúde ${ }^{11,12}$.

Em contrapartida levantaram-se vozes críticas que demonstraram sua preocupação ${ }^{13-15}$. A mais 
famosa foi a carta de 16 eticistas, médicos, enfermeiros e advogados que afirmavam que os pacientes preferiam não conversar sobre a morte e a incapacidade; que geralmente não sabem predizer seus desejos acerca do futuro; que as opiniões mudam e que o representante legal nem sempre é o melhor tradutor dos interesses do paciente ${ }^{16}$. Apesar do debate em relação a sua efetividade e os prós e contras de seu uso, a popularidade das DAV vem crescendo, sendo que nos EUA, atualmente, $70 \%$ de idosos formalizaram uma DAV ${ }^{17}$.

No Brasil, a Resolução CFM 1.995/12 dispõe sobre as diretivas antecipadas de vontade, um documento facultativo que poderá ser elaborado em qualquer momento da vida e da mesma maneira modificado ou revogado a qualquer instante ${ }^{1}$. 0 documento define DAV como o conjunto de desejos, prévia e expressamente manifestados pelo paciente, sobre cuidados e tratamentos que quer, ou não, receber no momento em que estiver incapacitado de expressar, livre e autonomamente, sua vontade ${ }^{1}$.

De acordo com a resolução o registro da DAV pode ser feito pelo médico na ficha médica ou no prontuário do paciente, desde que autorizado por este. Não são exigidas assinaturas nem testemunhas, haja vista que o médico - por conta de sua profissão - possui fé pública e seus atos têm efeito legal e jurídico ${ }^{1}$. Cumpre ressaltar que a resolução aponta que o médico deixará de levar em consideração as diretivas antecipadas de vontade do paciente ou representante que, em sua análise, estiverem em desacordo com os preceitos ditados pelo Código de Ética Médica ${ }^{1}$.

\section{Pano de fundo da DAV}

Apesar do escopo deste trabalho não ser o de discutir a respeito do campo moral que envolve as discussões de final de vida, consideramos importante discorrer de maneira sucinta sobre o ensejo do surgimento das DAV e do debate acerca de seus benefícios, obstáculos e limites.

Humanizar o morrer é uma questão básica subjacente a DAV. O empenho para promover a cultura da responsabilidade pela própria condição de finitude deve caracterizar quem consiga se perceber mortal e não queira existir mediante a negação dessa verdade ${ }^{18}$. Indubitavelmente, a medicina, a cultura médica que construímos, é também chamada a atender humanamente o final da vida, não somente a lutar contra a morte ${ }^{18}$.
Segundo Kovács ${ }^{19}$, o século XX evidenciou a mudança na trajetória da morte: na Idade Média era muito importante morrer rodeado por familiares e entes queridos, discutindo a vontade do moribundo após sua morte, firmando o testamento e a distribuição dos bens; hoje, ela é considerada tabu. Cada época tem como parâmetro uma forma de morte que aparece como a mais desejada e cada indivíduo idealiza de que maneira deseja morrer ${ }^{19}$. Quando o sujeito está saudável, entretanto, não reflete sobre sua finitude e só irá pensar no assunto quando for inevitável, geralmente quando acometido por doença terminal. Dessa forma, faz-se necessário estabelecer uma cultura que encare o processo da morte e do morrer de maneira construtiva ${ }^{19}$.

Marie de Hennezel, em A morte íntima, contribui para essa construção mediante reflexão e testemunho de sua experiência, por anos acompanhando pessoas que viviam seus últimos instantes: Morrer não é, como julgamos frequentemente, um tempo absurdo, desprovido de sentido (...) o tempo que precede a morte pode ser também de realização da pessoa e o da transformação ao seu redor (...) Quando nada mais se pode fazer, pode-se ainda amar e sentir-se amado ${ }^{20}$.

Os avanços científicos e tecnológicos das várias áreas do saber contribuíram para estigmatizar a morte, que, longe de ser vista como algo natural, passa a ser classificada como inimiga a ser vencida a qualquer preço ${ }^{21}$. Não podemos negar que esses avanços, principalmente na área da saúde, muito contribuíram para salvar mais vidas, revolucionando a qualidade de vida e longevidade humana; contudo, este desenvolvimento pode levar a um impasse quando se trata de buscar a cura e salvar uma vida, com todo empenho possivel, num contexto de missão impossível: manter uma vida na qual a morte já está presente ${ }^{22}$. Assim, a contrapartida dessa obstinação terapêutica atual acaba por destituir muitas pessoas de uma morte digna, haja vista vivermos em uma sociedade que nega a morte.

$\mathrm{Na}$ cultura em que vivemos, parece que o que não cura não serve e a arte do cuidar, que tem acompanhado os profissionais da saúde, parece ter sido abandonada em função de uma ciência que exige exatidão, eficácia e resultados para vencer as doenças, uma ciência que diante da morte se sente fracassada $^{18}$.

A tecnologia médica instiga discussões importantes na bioética, pois foi seu desenvolvimento que propiciou o prolongamento e a manutenção da vida, dando origem ao dilema entre a sacralidade da vida e a preocupação com sua qualidade, o que gera 
a questão sobre quando investir em tratamento e quando interrompê-lo ${ }^{22}$. Assim, temos por um lado o uso de todos os recursos disponíveis da medicina para prolongar a vida em detrimento de sua qualidade: a chamada distanásia, que segundo Pessini ${ }^{23}$ significa o prolongamento exagerado do processo de morte de um paciente ou tratamento fútil; por outro, a ortotanásia, que significa o não prolongamento artificial do processo de morte, além do que seria o processo natural ${ }^{24}$. Assim, é preciso priorizar a qualidade de vida que resta e encarar a morte como parte do processo natural da existência.

A consideração ética no processo de morrer supõe a tensão entre dois valores básicos: a inviolabilidade da vida humana e a exigência de morrer com dignidade humana ${ }^{18}$. Para Bermejo e Belda ${ }^{18}$, a expressão morte digna tem sido criticada e mal interpretada, por ter relação direta com a eutanásia, como se fosse uma porta aberta para se pensar nela. Para esses autores, porém, em seu significado não entra a discussão da apreciação ou recusa da eutanásia.

Nesse sentido, Lepargneur ${ }^{25}$, ao referir que o paciente com doença terminal ou não tem o direito legal e ético de recusar um tratamento que ache demasiadamente pesado, enfatiza que isto evitaria confundir a eutanásia contestável com a justa recusa da distanásia. O autor cita a afirmação do relatório anglicano On dying well de que é um erro empregar a palavra eutanásia para as decisões de não preservar a vida por meios artificiais, quando seria preferivel que se deixasse o doente morrer.

Para Blasco e colaboradores ${ }^{26}$, nos últimos anos o conceito de morte digna e o reconhecimento da obrigação ética e deontológica em saber identificar quando a morte é inevitável têm se fortalecido, momento em que a atenção deve focar no acompanhamento do paciente e família. Nesse marco de respeito à morte digna surge a necessidade de o paciente expressar sua vontade de forma antecipada - e que tal expressão seja válida quando o indivíduo não se encontrar em condições de fazê-lo ${ }^{26}$. Isto não significa o apressamento nem tampouco o prolongamento do processo de morte - a prática da eutanásia ou da distanásia - e cabe à bioética dirimir essas questões ${ }^{22}$. Mesmo porque em muitos países onde existe legislação acerca da DAV a prática da eutanásia não é permitida. Posto isso, pode-se dizer que este é um limite do presente documento.

As DAV ajudam o paciente a pensar na enfermidade e na morte e a conversar com o médico e seus entes queridos sobre essas questões; elas declaram como o indivíduo deseja que se desenvolva o processo de morrer e registram se permite intervenções clínicas como suporte de vida quando não existem expectativas de recuperação. Notificam também sobre o desejo de receber cuidados e tratamentos que irão paliar a dor e sintomas desagradáveis ${ }^{18,27}$, ressaltando-se que nesse processo é importante a comunicação entre as partes e que os profissionais de saúde informem e aconselhem adequadamente seus pacientes.

Devemos, portanto, entender que a DAV não pode ser uma espécie de lista de aprovação ou recusa de determinados tratamentos que não respondem às reais necessidades do paciente ${ }^{27}$. Embora não seja imprescindível, a pessoa pode também indicar um representante que, caso necessário, tomará as decisões por ela, baseando-se naquilo que sabe serem os seus desejos e expectativas ${ }^{18}$.

\section{Benefícios, obstáculos e limites}

\section{O cerne da DAV: a autonomia}

Tomar decisões considerando o que é melhor para o paciente quando este não consegue comunicar seus desejos é ocorrência diária e difícil para os médicos ${ }^{28}$. A importância da tomada de decisão informada e compartilhada pelo profissional de saúde que atende o paciente é essencial para a qualidade do cuidado e seus resultados. A literatura mostra que a participação do paciente no tratamento conduz a melhores resultados, o que vai ao encontro da antiga crença de que para a manutenção da saúde de uma pessoa enferma a base do cuidado é uma relação boa e confortável entre o médico e o paciente ${ }^{29}$.

Segundo Martinez ${ }^{27}$, o desacordo entre os profissionais de saúde e o paciente pode alongar a intervenção médica indefinidamente, prolongar a vida a qualquer preço, provocar confusão moral entre os profissionais, o doente e a família. Assim, diante de tais possibilidades as diretivas antecipadas são consideradas um meio proeminente de estender a autonomia do paciente em situações em que se encontra impossibilitado de exercê-la ${ }^{30}$.

Niebrój ${ }^{31}$ argumenta que durante os 40 anos da história da bioética como disciplina de conhecimento com especificidade própria as discussões sobre o princípio da autonomia têm evoluído. Inicialmente, a reflexão se concentrava na proteção do direito dos pacientes em participar diretamente da decisão sobre o cuidado que os envolvia, e a obrigação do médico em revelar a informação a respeito da natureza e consequência do tratamento era enfatizada. Nos dias atuais, os bioeticistas preferen- 
cialmente perguntam como informar pacientes de maneira a garantir que a informação revelada será entendida por eles e, consequentemente, capacitálos a consentir e autorizar o procedimento ou tratamento proposto ${ }^{8}$.

A autonomia em medicina, mais concretamente na ética médica e bioética, expressa o direito do paciente em definir o que seja ou não uma necessidade de saúde. Gracia ${ }^{32}$ esclarece que essa não é a autonomia kantiana, formal ou canônica, mas sim autonomia num sentido mais distinto, claramente deontológico. Em bioética, o que se entende por autonomia é a expressão de um direito. Desta forma, devemos aceitar que o usuário é quem hoje define, e certamente quem definirá no futuro, qual é a sua necessidade de saúde. Isso pode levar a todo tipo de arbitrariedade mediante a solicitação, pelo paciente, de coisas pouco racionais, que tenderão a trazerIhe frustração e a também desanimar o profissional de saúde ${ }^{32}$.

Tonelli ${ }^{33}$, em sua análise crítica das DAV, argumenta que a suposta proteção da autonomia é uma reivindicação muito fraca e esses documentos só fornecem benefício limitado para a prática clínica, visto que surgiram para garantir o controle dessas decisões ao paciente, assegurando sua autonomia. Contudo, deveria ter sido previsto que a intenção de transferir o poder de decisão para o paciente ou seu representante, sem considerar questões adjacentes relacionadas à prática clínica, resultaria em fracasso ${ }^{33}$. Hansot ${ }^{34}$ argumenta que, embora a intenção não seja a de retirar do paciente o processo de decisão, parece ingênuo acreditar que as DAV possam mudar a prática social da medicina estabelecida ou ajudar o doente a superar sua vulnerabilidade - é esperar muito desse documento, não importando quão bem elaborado esteja.

Caso a DAV reflita o desejo do paciente "controlar" sua morte, é importante verificar se esse desejo está baseado em uma compreensão quanto ao processo da morte ou ao medo que ela gera. $\mathrm{Da}$ mesma forma, é também necessário esclarecer se o paciente está em busca de controle ou de compaixão, apoio e presença confortante, haja vista que a negociação não nega a autonomia do paciente, mas é uma visão mais enriquecida do que constitui uma ação autônoma e autêntica ${ }^{35}$.

O atrativo e a promessa aparente das DAV é que possibilitam escolha, segurança e controle sobre a morte: o derradeiro exercício da autonomia ${ }^{35}$. Elas presumem que as preferências em relação ao cuidado são facilmente conhecidas pelos pacientes e mantidas pelos médicos ${ }^{36}$, mas essa concepção não considera as incertezas que existem na maioria das situações clínicas e menos ainda as influências sutis do poder mantido por aqueles que determinam quais opções serão oferecidas.

Ante tal fato, segundo Gilligan e Rafin ${ }^{36}$, podese argumentar que essas expectativas de escolha, segurança e controle são equivocadas, e propor que as DAV tenham função mais limitada, embora sem perder a vital necessidade de promover o processo de negociação necessário para o final da vida.

\section{A questionável estabilidade das decisões}

Parece lógico que as decisões devam ser tomadas com base no conhecimento e avaliação dos dados médicos, no prognóstico da doença e nos objetivos que devem ser negociados entre o paciente e os profissionais de saúde, e não sob a influência da enfermidade, do medo e da dor ${ }^{27}$. Forçar os pacientes a decidir sobre quais tratamentos deseja ou não receber nessas circunstâncias ou nomear um representante legal que o faça por ele talvez seja aceitável legalmente, mas é, pelo menos eticamente, problemático ${ }^{27}$.

Um premente problema ético no uso da DAV é que pessoas competentes podem nem sempre estar aptas para tomar decisões a respeito de seu futuro quando inopinadamente se deparam com o "seu eu incapacitado" ${ }^{30}$; em consequência, existe a preocupação com a autenticidade e estabilidade da decisão, visto que na elaboração do documento o paciente se baseia em uma reconstrução imaginária de como seria sua vida em determinada condição nunca antes experimentada. Essa reconstrução é altamente problemática pela dificuldade de prever fatos futuros. Haja vista a dificuldade na tomada de decisão sobre questões de saúde, especialmente no que concerne às diretivas antecipadas de vontade, deve-se ter em conta toda a incerteza subjacente a esse hipotético porvir ${ }^{37}$.

Pesquisa realizada por Schiff e colaboradores ${ }^{28}$, que teve como um dos objetivos determinar as experiências e opiniões dos geriatras sobre a DAV, identificou entre as preocupações adjacentes ao seu uso a possibilidade de existir mudança de sentimento quando se vivencia a situação antes apenas prevista e considerou inquietante o fato de o documento ser preenchido por alguém sem entendimento das implicações das decisões ou do quanto se pode estar influenciado por outras pessoas.

Vários estudos tentaram abordar a interrogação sobre tal persistência da vontade, e verificaram níveis altos de estabilidade em decisões relacionadas 
à preferência por tratamentos em cenários hipotéticos durante um período de até três anos, tanto para pacientes internados ${ }^{38}$ quanto para pacientes ambulatoriais ${ }^{39} \mathrm{e}$ em instituições de longa permanência ${ }^{40}$. Os resultados da pesquisa realizada por Schiff e colaboradores ${ }^{28}$ mostram que, da amostra de 1.426 geriatras, 842 responderam ao questionário e muitos tiveram uma experiência positiva cuidando de pacientes que tinham uma DAV. Apesar de reconhecer que existem problemas, muitos geriatras apoiam o uso desse documento para pessoas idosas.

Os principais efeitos positivos da DAV se relacionam com realizar o desejo do paciente por tratamentos menos invasivos, predominantemente paliativos no final de vida; facilitar as discussões de final de vida; ajudar no alcance de um consenso e fornecer clareza para outros membros da equipe multiprofissional e familiares com relação ao cuidado ${ }^{28}$. De acordo com Schiff e colaboradores ${ }^{28}$, poucos efeitos negativos foram descritos, entre eles o fato de haver situações em que o cuidado do paciente teve que ser transferido para outra equipe médica, devido a conflitos entre as convicções dos profissionais com aquelas expressas na DAV.

A literatura é confusa em relação à efetividade desses documentos. Estudos mais antigos revelaram que os mesmos tinham efeito mínimo nas decisões de impedir ou remover o cuidado ${ }^{41-45}$ e pouco contribuíam para aumentar a consistência do cuidado recebido e o desejo do paciente ${ }^{46}$. Estudo mais recente demonstrou que pacientes com DAV estão menos propensos a receber tratamento de suporte de vida ou de morrer no hospital ${ }^{47}$, mas ainda não se tem certeza se os resultados são consistentes com os desejos dos pacientes. Estudo prospectivo concluiu que os desejos previamente expressos eram seguidos em $75 \%$ dos casos, independentemente da existência de uma DAV ${ }^{46}$. Dados sobre a efetividade do uso de um representante legal mediante procuração para decidir sobre o cuidado de saúde são limitados.

Estudos relacionados à mudança de opinião de uma pessoa quando tem que enfrentar situação previamente prevista são raros devido à dificuldade em realizá-los. Pesquisa com médicos aposentados que apresentavam declínio funcional e/ou agravamento da depressão aponta que preferiram tratamento agressivo de suporte de vida, comparados com médicos de idade similar sem a presença desse declínio ${ }^{48}$. Schiff e colaboradores ${ }^{28}$ observam não ter encontrado nenhum estudo longitudinal sobre preferência de tratamento antes e depois de uma mudança relevante na saúde e, dessa forma, suge- rem que uma abordagem prática para essa incerteza é que os médicos incitem uma revisão regular do documento, particularmente quando existe mudança no estado de saúde.

Outros aspectos relevantes a serem considerados no preenchimento das DAV foram abordados pelo estudo realizado por Silveira e colaboradores ${ }^{4}$, que investigou a prevalência e os preditores da perda da capacidade de tomar decisões e da tomada de decisão ao final da vida, bem como a associação entre as DAV e o cuidado recebido, incluindo a concordância entre as preferências registradas e o tipo da decisão do representante legal tomadas no final de vida.

A pesquisa foi realizada por meio de entrevista com representantes legais de indivíduos de 60 anos ou mais que haviam falecido e que participaram do estudo de coorte intitulado Estudo de saúde e aposentadoria (Health and retirement study). As entrevistas foram realizadas até 24 meses após a morte do paciente. Dos 3.746 sujeitos representados por esses entrevistados $42,5 \%$ necessitaram de tomada de decisão, dentre os quais $70,3 \%$ tinham perdido a capacidade de decisão e 67,6\% tinham firmado uma DAV. Esse resultado mostra significativo aumento no uso das DAV desde o do estudo para entender prognóstico e preferências para resultados e riscos do tratamento (Support), realizado em $1996{ }^{49}$, que relatou que apenas $21 \%$ de pacientes muito doentes e hospitalizados tinham DAV. Os sujeitos que tinham uma DAV eram mais propensos a querer cuidado limitado $(92,7 \%)$ ou cuidado de conforto $(96,2 \%)$, ao invés de todo o cuidado possível (1,9\%); $83,2 \%$ dos sujeitos que requereram cuidado limitado e $97,1 \%$ dos sujeitos que requereram cuidado de conforto receberam o cuidado de acordo com suas preferências ${ }^{4}$.

O estudo também mostra que poucos sujeitos queriam cuidado agressivo, mas metade deles não o recebeu. Os autores argumentam que algumas pessoas podem concluir que esse achado indica que as DAV são utilizadas para renegar o cuidado de saúde preferido, mas essa seria uma interpretação errada dos dados, porque a análise estatística de regressão mostrou que o registro da preferência por tratamento agressivo aumentava significativamente a probabilidade de receber esse tipo de cuidado quando comparado com alguém que não o solicitou. $O$ que pode, então, explicar esse resultado?

Primeiro, o tratamento agressivo talvez não fosse a melhor opção para o paciente, apesar do desejo de recebê-lo. Segundo, dentre os sujeitos que requereram esse cuidado, a maioria tinha nomeado um representante legal para a tomada de decisão 
em seu lugar, os quais frequentemente passam por cima dos desejos dos pacientes - geralmente porque as circunstâncias requereram que fosse feito.

Os autores sugerem uma interpretação mais favorável para esses dados, ou seja, que as DAV têm importante efeito no cuidado recebido e que a nomeação de representante legal para tomadas de decisão sobre o cuidado de saúde é necessária para dar conta de fatores inesperados. Silveira e colaboradores ${ }^{4}$ argumentam que se aceitarmos que a nomeação de um representante legal é uma extensão da autonomia do paciente, então também temos que aceitar que sua decisão, mesmo contrária ao desejo do paciente, é baseada no que é o melhor para o paciente. Para que mais pacientes se beneficiem desses instrumentos valiosos os autores concluem que o sistema deveria assegurar aos provedores de saúde tempo, espaço e remuneração para conduzir essas discussões, que demandam tempo e são necessárias para planejar de maneira apropriada o cuidado no final de vida ${ }^{4}$.

\section{A terminologia ambígua utilizada na DAV}

Outro ponto contencioso sobre as DAV é abordado por Stone ${ }^{50}$, que em seu artigo escrutina os termos nelas utilizados, colocando quão difícil é defini-los de maneira que todos os entendam igualmente. $O$ autor relata que muitas DAV não contêm a definição ou o significado dos termos usados em sua descrição e adverte que sem uma definição de "doença terminal" no próprio documento a maioria dos assinantes entenderá apenas de forma vaga em que circunstâncias isso se aplica - mas, provavelmente, não terá sequer consciência de que desconhecem esse fato determinante.

O autor relata que na sua experiência como médico os familiares e o clero, com quem provavelmente o paciente discutirá o documento, não terão um entendimento melhor do que o termo significa, sendo que a maioria das pessoas que irá assinar o documento não sabe que existe um problema. A palavra "terminal", por exemplo, é muito vaga e pode abranger extensa gama de situações. O autor conta ter presenciado pessoas morrerem no ventilador mecânico contra a sua vontade, devido a quão elusivo o termo é ${ }^{50}$.

Stone ${ }^{50}$ também chama a atenção para a noção de tratamentos de suporte de vida que apenas servem para prolongar o processo de morte e contesta que isso não faz sentido. $O$ autor advoga que, no geral, assinar uma DAV não preserva a autonomia do paciente; ao invés disso, o coloca inteira- mente à mercê do médico, que decide se o paciente é competente para participar das decisões sobre seu tratamento, quanto tempo é relativamente um curto tempo e que define que tratamentos de suporte de vida são inevitáveis. Assim, explica o autor, se o paciente estiver em uma condição que o levará à morte cedo ou tarde e o médico responsável por seu tratamento acreditar que não vale a pena preservar sua vida, então o paciente tem uma "doença terminal" e qualquer intervenção médica que prolongue sua vida é "tratamento de suporte de vida", incluindo antibióticos, diálise e hidratação artificial. Caso o paciente se encontre na mesma condição, mas o médico responsável por seu tratamento acreditar que vale a pena preservar sua vida, então as intervenções que prolongam a vida do paciente não são "tratamentos de suporte de vida" e o paciente não está em "fase terminal".

Diante dessa perspectiva considera-se relevante a observação de Martinez ${ }^{27}$ sobre o fato de que uma DAV mal redigida ou mal interpretada pode adicionar uma camada técnica a mais a um processo já muito técnico e complicado de tomada de decisões; pode ser usada como instrumento para diminuir a responsabilidade que os profissionais e as instituições de saúde têm ante essas questões, bem como contribuir para que se sintam livres da carga de ter de se preocupar com seus pacientes. O autor argumenta, ainda, que embora as DAV tenham surgido para melhorar a comunicação entre o médico e o paciente de forma permanente, ao se refugiar numa norma ou regra geral, os médicos poderão utilizálas para se afastar facilmente da preocupação com a situação particular do paciente e simplesmente abandoná-lo ${ }^{18}$.

Ao preencher tal documento não podemos estar entregues a nós mesmos; a autonomia como solidão não é ética, ou seja, o paciente quer ser genuinamente respeitado, mas isso não significa abandoná-lo à própria sorte sem o devido cuidado e ajuda - atitudes capazes de beneficiá-lo em sua condição específica. O maior perigo que corre a atenção de saúde no século XXI não é o do paternalismo autocrático do médico, mas sim o abandono respeitoso do paciente ${ }^{27}$.

Além disso, a todo ser humano cabe o direito de participar no processo de deliberação de decisões que afetam sua vida, visto que o paciente é dotado de dignidade e deve ser respeitado e reconhecido como agente moral ${ }^{32}$. Porém, pontua Stone ${ }^{50}$, apesar de reconhecermos o dever de respeitar todos os seres humanos não sabemos como fazê-lo. Fagerlin e Schneider ${ }^{51}$ argumentam que para ser 
competente na elaboração da DAV o indivíduo tem que não somente possuir informação adequada sobre a natureza da doença e seus tratamentos (conhecimento médico), mas também buscar conhecer as circunstâncias não previstas que irão influenciar os futuros tratamentos e preferências do paciente (conhecimento profético). Niebrój ${ }^{31}$, contudo, pondera que a imprevisibilidade constitui elemento essencial e irremovível do humano/vida social.

Ante essas reflexões, o desafio é desenhar diretivas antecipadas que considerem a possibilidade de mudança nas respostas - e uma maneira seria rever o documento frequentemente com o paciente, quando a saúde piorar. Todavia, determinar qual a frequência, ou qual o evento ou indicador que deveria catalisar o retorno para essa discussão, não é tarefa fácil ${ }^{52}$.

Outra abordagem se baseia na distinção promovida por Fins et al. ${ }^{53}$, intitulada contrato versus pacto, na qual o processo de planejamento de cuidado antecipado mostra-se diferenciado. Alguns indivíduos esperam que seus desejos sejam realizados exatamente como especificaram (contrato); outros, para terem seus valores fundamentais entendidos e colocados em prática, necessitam que se averigue se a ação (tratamento/procedimento que será realizado) contraria ou não a afirmação ou preferência expressa em sua DAV (pacto). Claramente, argumenta Schwatz ${ }^{54}$, para o propósito de planejamento de cuidado o profissional de saúde deseja saber, com bastante antecedência, as preferências dos pacientes e representantes para contrato ou pacto e no que eles concordam. Além disso, ajudaria saber se, em geral, as preferências expressas por contrato ou pacto comportam a probabilidade de o paciente mudar de ideia a respeito do tratamento de suporte de vida, caso descubra que a doença em estado avançado é mais suportável que o previsto ${ }^{55}$.

\section{Abordagens alternativas}

Nesse contexto multifacetado destaca-se a abordagem denominada Advanced Care Planning (ACP) - Planejamento Antecipado do Cuidado, que redireciona o foco de simplesmente o paciente expressar preferência ou recusa por determinadas intervenções, tais como diálises, ventilação mecânica, alimentação por sonda e hidratação, para as metas do cuidado. Messinger-Rapport, Baum e Smith ${ }^{56}$ advogam a nomeação de um procurador ou representante legal, visto que a procuração para decisões médicas é mais flexível e amplamente aplicada que o testamento vital. Os autores argumentam que abordar o paciente oferecendo uma lista de trata- mentos de suporte de vida, antes de discutir as metas do cuidado e o prognóstico, é o mesmo que colocar a carruagem antes dos cavalos e ameaça tirar o foco da necessidade de indagar sobre os valores e oferecer o cuidado apropriado ${ }^{56}$.

Segundo Pearlman e colaboradores ${ }^{57}$, na abordagem do ACP os indivíduos formulam suas preferências baseados nas considerações sobre a qualidade de vida na sua condição atual e/ou numa situação de saúde previsível (ex. doença terminal) e os benefícios e a sobrecarga dos tratamentos de suporte de vida. Esses valores e preferências são então comunicados aos familiares próximos ou representantes em potencial, que tomarão as decisões para o paciente e a equipe provedora de saúde. O último passo é documentar esses valores e preferências por meio das diretivas antecipadas. Os autores reconhecem que existem barreiras em relação à ACP devido à relutância social de pensar sobre o morrer ${ }^{57}$.

Nenhuma das intervenções realizadas para tratar dessas barreiras assegura um ACP global ou melhora o mais importante resultado, que é o entendimento compartilhado dos valores e desejos do paciente pelos provedores de saúde ou pela pessoa indicada para tomar a decisão em seu lugar ${ }^{57}$. Pearlman e colaboradores ${ }^{57}$ observam que as DAV talvez não sejam apropriadas para todos; assim, os médicos deveriam de maneira eficiente ter como alvo os pacientes que podem se beneficiar das diretivas, isto é, aqueles em risco de perder a capacidade de decisão (ex. pacientes com demência, doença terminal, fragilidade ou com antecedente de AVC) e aqueles que estão distantes ou não têm um núcleo familiar.

Nesse sentido, Hawkins e colaboradores 58 chamam a atenção para o fato de, apesar de as DAV estarem cada vez mais detalhadas para salvaguardar maior autonomia do sujeito, existir um aumento de evidências sugerindo que os pacientes não desejam de fato exercer esse tipo de controle sobre as decisões relacionadas ao final de vida. Nos anos recentes, relatam os autores, maior atenção tem sido dada às DAV orientadas para os valores e para aquelas que consideram a importância dos laços familiares no planejamento dos cuidados relacionados ao final de vida. Os autores realizaram um estudo que teve como propósito examinar as atitudes dos pacientes e seus representantes legais a respeito do uso da DAV para o manejo dos tratamentos relacionados ao final de vida. Trezentos e trinta e sete idosos com idade superior a 65 anos, que participavam de outro estudo longitudinal sobre as DAV e seus substitutos, foram entrevistados. Os resultados revelaram que poucos indivíduos desejavam registrar 
suas preferências por tratamentos médicos específicos e exigir que fossem seguidos, ipsis litteris, próximo ao período da morte.

O desejo da maioria dos entrevistados era expressar preferências de maneira geral, tais como valores e metas do cuidado, em adição a/ou em lugar de preferências por tratamentos médicos específicos, e também permitir ao representante legal certa liberdade no processo de tomada de decisão ${ }^{58}$. Ou seja, os pacientes se mostraram mais interessados em transmitir seus valores e metas de cuidado do que especificar tratamentos e intervenções. Mais da metade disse que era definitivamente necessário registrar seus desejos na DAV. Os autores apontam, contudo, que o formato da maioria desses documentos não reflete essa prioridade e advertem ser importante que os profissionais e provedores de saúde, bem como os pesquisadores e os responsáveis pelas políticas públicas, reconheçam essa possibilidade.

\section{Considerações finais}

Essas informações relatam muitos benefícios, obstáculos e limites da utilização da DAV, mas apesar de suas dificuldades tudo indica que sua utilização será cada vez maior, o que faz com que o foco do debate se desloque para seu uso de maneira efetiva.
Sob um olhar otimista pode-se dizer que existe um ponto de interseção entre os argumentos contra e a favor, ou seja, que esses documentos devam integrar um processo que propicie um diálogo aberto entre familiares, médicos e o paciente, de maneira a refletir as reais necessidades, crenças, valores, metas de cuidado e preferências do paciente.

Posto isso, e apesar de a Resolução CFM 1.995/12 ter sido formulada mais de 40 anos após o surgimento do chamado testamento vital, destacase a importância de que o Brasil aprenda com as experiências de outros países para assegurar uma legislação que encoraja relacionamentos positivos e bem informados entre a equipe médica e seus pacientes a respeito de suas preferências por cuidados ao final de vida. Nesse processo é importante que as limitações das DAV sejam reconhecidas e entendidas para que realmente possam contribuir para a qualidade do cuidado a se prestar no final da vida, e que sejam de fato usadas a serviço da autonomia possível das pessoas em seu processo de morte.

Para que isso aconteça concluímos ser premente a realização de estudos no Brasil que venham iluminar e esclarecer as diversas facetas desse tema complexo, de modo a contribuir para uma proposta mais ampla de realmente estabelecer uma cultura que encare o processo da morte e do morrer de maneira mais construtiva, e a morte digna não seja somente um conceito, mas se torne realidade.

Trabalho produzido no âmbito do programa de pós-graduação em Bioética pelo Centro Universitário São Camilo.

\section{Referências}

1. Conselho Federal de Medicina. Resolução CFM n 1.995, de 31 de agosto de 2012. Dispõe sobre as diretivas antecipadas de vontade dos pacientes. [Internet]. 2012 (acesso 5 jan. 2013). Disponível: http://www.portalmedico.org.br/resolucoes/CFM/2012/1995_2012.pdf

2. Lopes AD, Cuminale N. O direito de escolher. Revista Veja. São Paulo: Editora Abril; 2012. Ano 45, $n^{\circ}$ 37. p. 98-106.

3. Brown BA. The history of advance directives: a literature review. J Gerontol Nurs. 2003;29(9):414.

4. Silveira MJ, Kim SYH, Kenneth M, Langa MK. Advance directives and outcomes of surrogate decision making before death. N Engl J Med. 2010;362:1.211-8.

5. Ashby $M$, Wakefield $M$, Beilby J. General practitioners' knowledge and use of living wills. BMJ. 1995;310(6.974):230.

6. Fuchs VR. The growing demand for medical care. N Engl J Med. 1968;279(4):190-5.

7. National Library of Medicine. Advance directives. 1991 (acesso 10 dez. 2012). Disponível: http:// www.ncbi.nlm.nih.gov/mesh/?term=advance+directives

8. Beauchamp TL, Childress JF. Principles of biomedical ethics. $4^{\text {a }}$ ed. New York: Oxford University Press; 1994.

9. Toller CA, Budge MM. Compliance with and understanding of advance directives among trainee doctors in the United Kingdom. J Palliat Care. 2006;22(3):141-6.

10. Bogardus ST, Bradley EH, Williams CS, Maciejewski PK, van Doorn C, Inouye SK. Goals for the care of frail older adults: do caregivers and clinicians agree? Am J Med. 2001;110(2):97-102. 
11. Greco PJ, Schulman KA, Lavizzo-Mourey R, Hansen-Flaschen J. The patient self-determination act and the future of advance directives. Ann Intern Med. 1991;115(8):639-43.

12. Singer PA, Siegler M. Advancing the cause of advance directives. Arch Intern Med. 1992;152(1):224.

13. Emanuel LL, Barry MJ, Stoeckle JD, Ettelson LM, Emanuel EJ. Advance directives for medical care: a case for greater use. N Engl J Med. 1991;324(13):889-95.

14. Emanuel LL, Emanuel EJ. The medical directive: a new comprehensive advance care document. Jama. 1989;261(22):3.288-93.

15. Kelner MJ, Bourgeault IL. Patient control over dying: responses of health careprofessionals. Soc Sci Med. 1993;36(6):757-65.

16. Lo B, McLeod GA, Saika G. Patient attitudes to discussing life-sustaining treatment. Arch Intern Med. 1986;146(8):1.613-5.

17. Teno JM, Gruneir A, Schwartz Z, Nanda A, Wetle T. Association between advance directives and quality of end-of-life care: a national study. J Am Geriatr Soc. 2007;55(2):189-94.

18. Bermejo JC, Belda RM. Testamento vital: diálogo sobre la vida, la muerte y la libertad. Madrid: PPC Editorial; 2011.

19. Kovács MJ. Autonomia e o direito de morrer com dignidade. Bioética. 1998;6(1):61-9.

20. Hennezel M. A morte íntima. $2^{\mathrm{a}}$ ed. São Paulo: Ideias e Letras; 2004.

21. Esslinger I. O paciente, a equipe de saúde e o cuidador: de quem é a vida, afinal? Um estudo acerca do morrer com dignidade. In: Pessini L, Bertachini L, organizadores. Humanização e cuidados paliativos. São Paulo: Loyola/Centro Universitário São Camilo; 2004.

22. Kovács MJ. Bioética nas questões da vida e da morte. [Internet]. Psicol USP. 2003 (acesso 13 dez. 2013);14(2):115-7. Disponível: http://www.scielo.br/scielo.php?script=sci_arttext\&pid=S010365642003000200008

23. Pessini L. Distanásia: até quando prolongar a vida? São Paulo: Centro Universitário São Camilo/ Loyola; 2001.

24. Junges JR, Cremonese C, Oliveira EA, Souza LL, Backes V. Reflexões legais e éticas sobre o final da vida: uma discussão sobre a ortotanásia. [Internet]. Rev. bioét. (Impr.). 2010 (acesso 20 jun. 2014);18(2):275-88. Disponível: http://revistabioetica.cfm.org.br/index.php/revista_bioetica/ article/view/564/537

25. Lépargneur $\mathrm{H}$. Bioética da eutanásia: argumentos éticos em torno da eutanásia. [Internet]. Bioética. 1999 (acesso 19 jun. 2014);7(9):41-8. Disponível: http://revistabioetica.cfm.org.br/ index.php/revista_bioetica/article/view/292/431

26. Blasco AC, Montfort FC, Palomar RM. Conocimientos y actitudes de los profesionales de los equipos de atención primaria sobre el documento de voluntades anticipadas. Aten Prim. 2010;42(9):463-9.

27. Martínez K. Los documentos de voluntades anticipadas. Anales Sis San Navarra. 2007;30(3 Suppl):87-102.

28. Schiff R, Sacares P, Snook J, Rajkumar C, Bulpitt CJ. Living wills and the mental capacity act: a postal questionnaire survey of UK geriatricians. Age Ageing. 2006;35(2):116-21.

29. Balint JA. Brief encounters: speaking with patients. Ann Intern Med. 1999;131(3):231-4.

30. Fazel S, Hope T, Jacoby R. Assessment of competence advance directives: validation of a patient centred approach. BMJ. 1999;318(7182):493-7.

31. Niebrój LT. Advance directives and the concept of competence: are they a moral barrier to resuscitation? J Physiol Pharmacol. 2007;(5 Suppl):477-84.

32. Gracia D. Pensar a bioética: metas e desafios. São Paulo: Loyola; 2012.

33. Tonelli MR. Pulling the plug on living wills: a critical analysis of advance directives. Chest. 1996;110(3):816-22.

34. Hansot E. A letter from a patient's daughter. Ann Intern Med. 1996;125(2):149-51.

35. Drought TS, Koenig BA, Raffin TA. Advance directives: changing our expectations. Chest. 1996;110(3):589-91.

36. Gilligan T, Raffin TA. Whose death is it, anyway? Ann Intern Med. 1996;125(2):137-41.

37. Tulsky JA, Chesney MA, Lo B. How do medical residents discuss resuscitation with patients? J Gen Intern Med. 1995;10(8):436-42.

38. Patrick DL, Pearlman RA, Starks HE, Cain KC, Cole WG, Uhlmann RF. Validation of preferences for life-sustaining treatment: implications for advance care planning. Ann Intern Med. 1997;127(7):509-17.

39. Emanuel LL, Emanuel EJ, Stoeckle JD, Hummel LR, Barry MJ. Advance directives: stability of patients' treatment choices. Arch Intern Med. 1994;154(2):209-17.

40. Bosshard G, Wettstein A, Bar W. How stable is the attitude of aged people towards lifeextending measures? Results of a 3-year follow-up in nursing home residents. Z Gerontol Geriatr. 2003;36(2):124-9.

41. Smedira NG, Evans BH, Grais LS, Cohen NH, Lo B, Cooke M et al. Withholding and withdrawal of life support from the critically ill. N Engl J Med. 1990;322(5):309-15.

42. Schneiderman LJ, Kronick R, Kaplan RM, Anderson JP, Langer RD. Effects of offering advance directives on medical treatments and costs. Ann Intern Med. 1992;117(7):599-606. 
43. Teno JM, Lynn J, Phillips RS, Murphy D, Youngner SJ, Bellamy P et al. Do formal advance directives affect resuscitation decisions and the use of resources for seriously ill patients? J Clin Ethics. 1994;5(1):23-30.

44. Lo B, Saika G, Strull W, Thomas E, Showstack J. 'Do not resuscitate' decisions: a prospective study at three teaching hospitals. Arch Intern Med. 1985;145(6):1.115-7.

45. Goodman MD, Tarnoff M, Slotman GJ. Effect of advance directives on the management of elderly critically ill patients. Crit Care Med. 1998;26(4):701-4.

46. Danis M, Southerland LI, Garrett JM, Smith JL, Hielema F, Pickard CG et al. A prospective study of advance directives for life sustaining care. N Engl J Med. 1991;324(13):882-8.

47. Degenholtz HB, Rhee YJ, Arnold RM. Brief communication: the relationship between having a living will and dying in place. Ann Intern Med. 2004;141(2):113-7.

48. Straton JB, Wang NY, Meoni LA, Ford DE, Klag MJ, Casarett D et al. Physical functioning, depression, and preferences for treatment at the end of life: the Johns Hopkins precursors study. J Am Geriatr Soc. 2004;52(4):577-82.

49. Pritchard RS, Fisher ES, Teno JM, Sharp SM, Reding DJ, Knaus WA et al. Influence of patient preferences and local health system characteristics on the place of death. J Am Geriatr Soc. 1998;46(10):1.242-50.

50. Stone J. Advance directives, autonomy and unintended death. Bioethics. 1994;8(3):223-46.

51. Fagerlin A, Schneider CE. Enough: the failure of the living will. Hastings Cent Rep. 2004;34(2):3042.

52. Das AK, Mulley GP. The value of an ethics history? J R Soc Med. 2005;98(6):262-6.

53. Fins JJ, Maltby BS, Friedmann E, Greene MG, Norris K, Adelman R et al. Contracts, covenants and advance care planning: an empirical study of the moral obligations of patient and proxy. J Pain Symptom Manage. 2005;29(1):55-68.

54. Schwartz C. Decision making at the end of life: shifting sands. J R Soc Med. 2005;98(7):297-8.

55. Schwartz CE, Wheeler HB, Hammes B, Basque N, Edmunds J, Reed G et al. Early intervention in planning end-of-life care with ambulatory geriatric patients: results of a pilot trial. Arch Intern Med. 2002;162(14):1.611-8.

56. Messinger-Rapport BJ, Baum EE, Smith ML. Advance care planning: beyond the living will. Cleve Clinic J Med. 2009;76(5):276-85.

57. Pearlman R, Starks H, Cain KC, Cole WG. Improvements in advance care planning in the veterans affairs system: results of a multifaceted intervention. Arch Intern Med. 2005;165(6):667-74.

58. Hawkins NA, Ditto PH, Danks JH, Smucker WD. Micromanaging death: process preferences, values, and goals in end-of-life medical decision making. Gerontologist. 2005;45(1):107-17.

Participação dos autores

Maria Inês Nunes - elaboração do artigo; Márcio Fabri dos Anjos - leitura crítica e correção final.

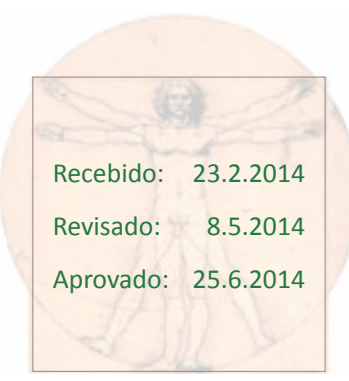

